\title{
Medical audit: in need of evaluation
}

\author{
Kieran Walshe, James Coles
}

In 1976, two years after the introduction of mandatory quality assurance in the United States healthcare system ${ }^{1}$ and at a time of growing debate about the benefits of that investment, ${ }^{2}$ Charles Phelps, an American economist, wrote:

"The evidence used to justify these various regulations of quality has been, to be generous, sparse. The primary justification for many of these programs is that the present state of affairs is scandalous, so that change must lead to improvement. While not necessarily quarrelling with the premise, the conclusion is unwarranted. It therefore seems appropriate to begin to evaluate the evaluators, to develop a framework with which one could assess the gains to society from undertaking a quality assurance program of one type or another." ${ }^{3}$

\section{Continuing need for evaluation}

Seventeen years later, at the International Society for Quality Assurance in Healthcare (ISQA) conference in Maastricht in June 1993, a panel of eminent quality assurance specialists from the United States was asked what evidence existed to show that the massive annual investment in quality assurance there has resulted in a higher quality of care. The specialists answered that, put plainly, there was little or no evidence. They were also asked whether it had been shown that hospitals which met the Joint Commission for the Accreditation of Healthcare Organisations' (JCAHO) quality standards actually provided better quality care than those that did not. Although the vast majority of hospitals in the United States undergo the costly and time consuming accreditation process, and have been doing so for decades, the specialists replied that very few studies had actually examined the link between accreditation status and quality of care and that there was no conclusive evidence that a link existed. Clearly, in the United States Charles Phelps' call for the proper evaluation of quality assurance programmes fell on deaf ears.

\section{Lessons for the United Kingdom}

What lessons are there in this for the United Kingdom? Over the past three years the Department of Health has spent about $£ 140 \mathrm{~m}$ on developing a medical audit programme in England. ${ }^{4}$ In a relatively short space of time structures and systems for medical audit have been established to a greater or lesser extent in every healthcare provider in the hospital and community health services. There can be few medical professionals in clinical practice who have not become involved in, or at least aware of, medical audit. For any programme of this size, complexity, and potential impact, evalu- ation is virtually a necessity - if only to map progress against objectives and to account for use of resources. However, for the medical audit programme, evaluation is particularly important for other reasons, as follows.

- Although there is evidence of the efficacy of medical audit (that audit can produce quality improvements), there is little evidence of its effectiveness (that, in general, audit programmes do yield quality improvements). The only source of that kind of evidence is programme evaluation.

- The medical audit programme is at a crossroads: the future funding mechanisms and funding levels for medical audit are unclear, and many organisational issues (such as the roles of purchasers, the form of multiprofessional involvement, and the place of managerial participation) are unresolved. Evaluation is needed to inform the future development of the programme.

- Our current understanding of how and why medical audit is (or is not) successful in producing quality improvements is very limited. We need to identify the characteristics of good practice in audit, and understand the underlying mechanisms, if we are to improve the effectiveness of the audit programme. To do that requires a structured evaluative approach.

- It is evident that those with an interest or involvement in the programme - clinicians, managers, and audit staff, from both providers and purchasers - are increasingly keen to see the results of the programme evaluated. Without that evaluation their willingness to continue to participate or invest in medical audit may begin to diminish.

- There are many competing demands for healthcare resources, of which medical audit is only one. Expenditure on medical audit has an opportunity cost which cannot be ignored, and eventually that expenditure has to be justified through evaluation.

It can be argued that it is too soon to expect the medical audit programme to have borne fruit in the shape of widespread improvements in the quality of care. But evaluation cannot be delayed for long because of the growing need for the results of evaluative studies to steer the future of the programme. In any case, those studies can take account of and make allowances for the relatively recent introduction of medical audit in the way they approach evaluation.

\section{Review of evaluations}

Of course, some evaluation of the medical audit programme is already under way. In a 
recent review of evaluation initiatives relating to medical and clinical audit, carried out for the Department of Health, ${ }^{5}$ we found a total of twenty current or recent studies, ranging from some focused on individual audit projects or departments to others with a much wider regional or national remit.

We found that current evaluation activity was quite limited, given the size of the programme, and was largely the preserve of external researchers rather than regions, purchasers, and providers themselves. There were few readily available tools or techniques for evaluation, which partly contributed to the limited level of activity. Most current evaluations were focused on medical audit, to the exclusion of clinical audit and quality assurance, and most evaluations were dominated by the provider-clinician perspective, with little or no manager, purchaser, or consumer input. There was little formal evaluation of audit programmes above provider level, such as in regions and national bodies. Despite the existence of annual planning and reporting mechanisms, there was little information about the audit programme across the NHS in England available in a consistent format which could support aggregations and comparisons. Few evaluative studies had considered the costs and benefits of audit in a way which would inform the debate on the future investment of healthcare resources in audit. Although regions were well placed to undertake and coordinate evaluations, few had done so beyond simply gathering and monitoring information in the annual planning and reporting cycle. Finally, we concluded that evaluators needed to be proactive, and do more than simply disseminate their findings through publications, if they were really to influence the future development of audit.

\section{National evaluations}

Two national evaluations of the audit programme are currently in progress: one commissioned by the Department of Health and being carried out by CASPE Research, and the other being undertaken independently by the National Audit Office.

The National Audit Office evaluation is focused on the clinical audit programme in England, Wales, and Scotland, and its primary aim is to identify the extent to which patients have benefited from the introduction of audit. To do this representatives will be visiting a selection of authorities in each country, starting in Scotland, and they will produce a separate report for each country.

CASPE Research has been commissioned by the Department of Health to undertake an evaluation of the medical audit programme in the hospital and community health services in England. The CASPE project consists of a series of separate but interlinked subprojects or research strands, each directed at a different area of the evaluation of the medical audit programme. For example, we plan to map the progress of the programme across all health- care providers; to assess the roles and involvement of purchasers in the programme; to examine regionally and nationally based initiatives within the programme; to undertake a detailed review of the progress, impact, and costs of the programme from various perspectives; to assess the mechanisms for monitoring and reporting within the programme; to identify some models of good practice in audit; to develop some evaluative tools for use by others in evaluating audit programmes; and to examine the impact of audit programmes on provider performance. These research strands will be served by a combination of data collection mechanisms, including postal surveys, site visits, case studies, and the use of existing data obtained from various sources. They are linked together within an overall evaluative framework developed at the beginning of the project. ${ }^{6}$ The research strands are designed to build up into an extensive evaluation of the medical audit programme, which addresses a range of programme attributes from various perspectives and at several organisational levels.

The CASPE project is being overseen by an advisory panel, made up of representatives of the Department of Health and the Clinical Outcomes Group. We are keen to use to the full the understanding and experience of those involved in the medical audit programme, and we will be asking them to contribute by responding to surveys and hosting site visits. We plan to produce a series of evaluation reports during the project and to ensure that the audit staff, clinicians, and managers who participate in the data collection will receive copies of those reports as soon as they become available.

\section{Conclusions}

Like Charles Phelps, we believe that proper evaluation is crucial to the development of quality assurance and medical and clinical audit. Large scale projects such as the CASPE Research and National Audit Office studies have an important role, but evaluation needs to be incorporated into audit projects and programmes at every level. If audit is to become a continuing and embedded part of clinical practice it should do so on its demonstrated merits, rather than through an act of blind faith.

For more information about the CASPE Research evaluation of the medical audit programme in the hospital and community health services in England, please contact CASPE Research, 22 Palace Court, Bayswater, London W2 4HU (Tel 071 229 8739).

1 Sanazaro PJ. Medical audit: experience in the USA. BMF $1974 ; \mathrm{i}: 271-4$

2 Komaroff A. The PSRO quality assurance blues. New Engl f Med 1978;298:1194-6.

3 Phelps CE. Benefit/cost analysis of quality assurance programs. In: Egdahl RH, Gertman PM, eds. Quality programs. In: Egdahl RH, Gertman PM, eds. Quality assurance in health care. Germantown

4 Department of Health. Medical audit in the hospital and community health services. London: DOH, 1991. community

5 Walshe K, Coles I. Evaluating audit: a review of initiatives. London: CASPE Research, 1993.

6 Walshe K, Coles J. Evaluating audit: developing a framework. London: CASPE Research, 1993. 